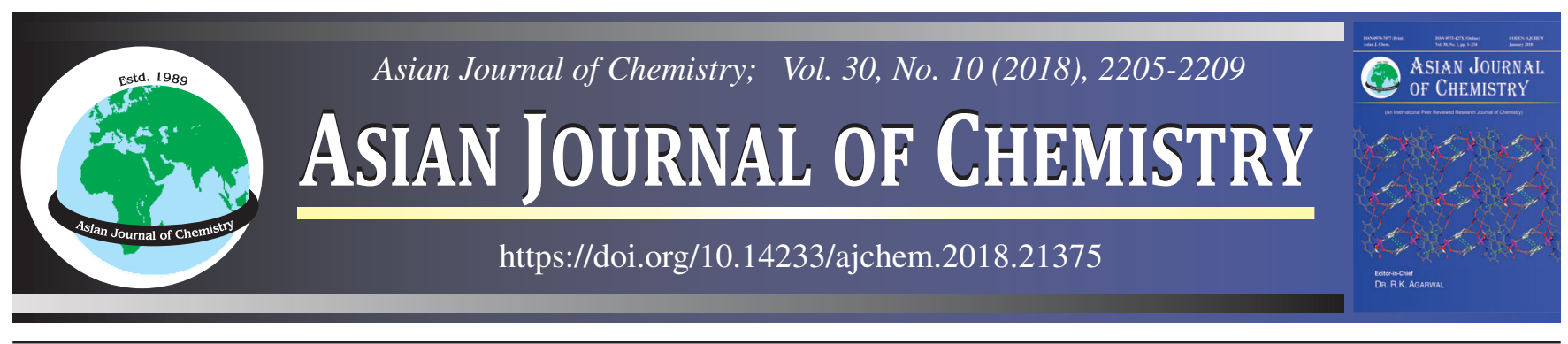

\title{
Biodegradability Nature of Polybenzimidazole Analogs by Modulating Two Histidine Degradation Enzymes (Urocanase and Formiminoglutamase): in silico Approach
}

\section{ViJayakumar VeEraragavan $^{1}$, RAmeshimumar Chidambaram ${ }^{1, *}$ and Radhakrishnan Narayanaswamy ${ }^{2,3, *}$}

${ }^{1}$ Organic Chemistry Laboratory, Department of Chemistry, Vel Tech Rangarajan Dr. Sagunthala R \& D Institute of Science and Technology, Avadi, Chennai-600 062, India

${ }^{2}$ Bio Incubator, Vel Tech Technology Incubator (Vel Tech TBI) Vel Tech Rangarajan Dr. Sagunthala R \& D Institute of Science and Technology, Avadi, Chennai-600 062, India

${ }^{3}$ Department of Biotechnology, Vel Tech Rangarajan Dr. Sagunthala R \& D Institute of Science and Technology, Avadi, Chennai-600 062, India

*Corresponding authors: E-mail: nscrameshkumar@gmail.com; nrkishnan@gmail.com

Biodegradation pathway of substituted imidazole compounds has been reported to have close analogue to histidine degradation pathway. The present study carried out on four different types of polybenzimidazole (PBI) analogs such as $m$-PBI (where $\mathrm{n}=1,2$ and 3 ), $p$-PBI (where $n$ $=1,2$ and 3), pyridine- $m$-PBI (where $n=1,2$ and 3) and alkylated- $m$-PBI (where $n=1,2$ and 3). These polybenzimidazole analogs were evaluated on the docking behaviour of urocanase and formiminoglutamase (FIGase) using PatchDock. Besides, molecular physico-chemical, drug-likeness, ADME (absorption, distribution, metabolism and excretion analyses) were studied. ADME analysis showed that $m$-PBI (where $\mathrm{n}=1$ ) and pyridine- $m$-PBI (where $\mathrm{n}=1$ ) predicated to have cytochrome P450 (CYP1A2, CYP2C19, CYP2D6 and CYP3A4) inhibition effect. Docking studies revealed that alkylated- $m$-PBI (where $\mathrm{n}=2$ ) showed the least atomic contact energy $(-123.83 \mathrm{kcal} / \mathrm{mol})$ with that of urocanase. Similarly, $m$-PBI (where $\mathrm{n}=1$ ) showed the least ACE $(-123.83 \mathrm{kcal} / \mathrm{mol})$ with that of formiminoglutamase.

Keywords: Polybenzimidazole polymer, Molecular docking, Urocanase, Formiminoglutamase.

\section{INTRODUCTION}

Growths in science and technology, exclusively past 10 years, have augmented the quantity of artificial polymers fashioned universal a piece year. Around 140 million tons of artificial polymers are generated. The presence of materials in the atmosphere brings about significant difficulties, in addition to a test for wastewater management plants and contamination of groundwater and surface water. Artificial polymers are documented as main solid waste ecological contaminants [1].

Polybenzimidazoles (PBI) are linear aromatic heterocyclic polymers with benzimidazole repeating units, which exhibits excellent thermal stability, resistance to chemicals. Polybenzimidazoles have synthesized by condensation polymerization of 3,3',4,4'-tetraaminobiphenyl and aliphatic diacids or derivatives in the presence of polyphosphoric acid at higher temperature. The fundamental research work on these polymers in the early stage development was carried out in Dupont and Hoechst Celanese Research Co by NASA and U.S. Air force Materials Laboratory [2-4]. Before the 1980s the majority of polybenzimidazole applications were restricted on fire blocking applications, thermal protective clothing, high temperature matrix resins and reverse osmosis membranes. Polybenzimidazole has been lengthily discovered in the area of membrane partioning methodologies for fuel cells [5-7], nanofiltration [8], reverse osmosis [9], forward osmosis [10], metal extraction [11-13], protein extraction [14], nevertheless one major disadvantage of polybenzimidazole based polymer is difficult of liquefying it in mutual organic diluents. Polybenzimidazole has only limited solubility in a few highly polar and aprotic organic solvents such as dimethyl sulfoxide, $\mathrm{N}, \mathrm{N}$-dimethylacetamide, $N, N$-dimethylformamide and concentrated acids. These diluents are comparatively poisonous and explosive, which are dangerous to both operators and atmosphere. Furthermore, PBI has dissolving some superior circumstances, i.e.,

This is an open access journal, and articles are distributed under the terms of the Creative Commons Attribution-NonCommercial 4.0 International (CC BY-NC 4.0) License, which allows others to copy and redistribute the material in any medium or format, remix, transform, and build upon the material, as long as appropriate credit is given and the new creations are licensed under the identical terms. 
high pressure as well as high temperature, which is above the boiling point, these organic solvents also toxic in nature that causes environmental pollutions [15]. These limit the growth potential of polybenzimidazole based polymers but also nondegradable nature of these polymeric resins. Growing quantities of artificial polymers generated results in growing interest in polymer biodegradation.

In earlier studies, four types of polybenzimidazole based polymeric resins were investigated for the extraction of metal ions such as uranium, thorium, palladium and radioactive metals such as $\mathrm{Am}$ (III), $\mathrm{Pu}(\mathrm{IV}), \mathrm{Eu}(\mathrm{III})$ as a role of $\mathrm{HNO}_{3}$ concentration and also investigated column chromatography separation of these metal ions from simulated waste solution. These results revealed that polybenzimidazole based polymer resins are suitable candidate for recovery of metal ions from actual nuclear waste materials [16]. But these polybenzimidazole polymeric resins were insoluble in organic solvents. Hence, there is a need for the alternative solvents or degradation pathways. The biodegradation pathway of imidazole ring compounds has been reported to have close analogues to the histidine degradation pathway. MetaCyc database (http:/metacyc.org) has highlighted three important histidine catabolism/degradation pathways. Urocanase and formiminoglutamase (FIGase) are two key enzymes plays important role in histidine degradation pathway [17].

To our best of knowledge, there is no literature for predicting the degradability nature of polybenzimidazole based polymers. In present study, we have selected four PBIs with different units and evaluated on the docking behaviour of urocanase and formiminoglutamase (FIGase) biodegradation enzyme. The results analyzed using PyMOL software shown that the useful information to predict the biodegradable potential of polybenzimidazole based polymers. Furthermore, molecular physico-chemical, drug-likeness, absorption, distribution, metabolism and excretion analysis (ADME) were done.
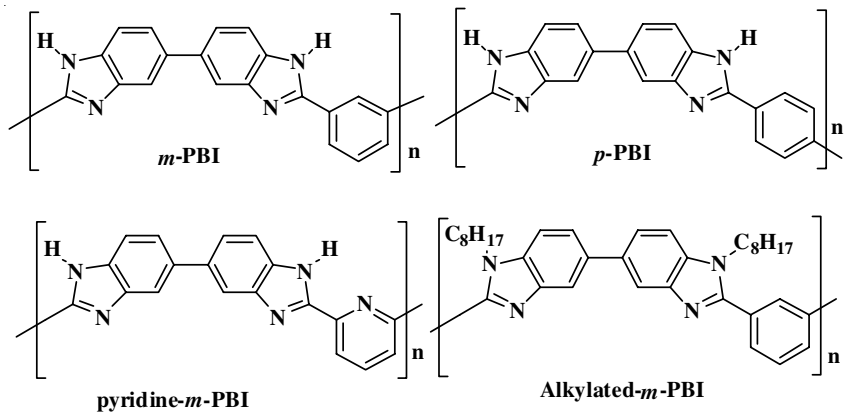

Fig. 1. Structure of synthesized polybenzimidazole polymeric resins

\section{EXPERIMENTAL}

Ligand preparation: Polybenzimidazole structures were drawn in ChemBioDraw Ultra 12.0 while molecular mechanic minimization of ligands carried out by ChemBio 3D Ultra 12.0, according to the reported procedure [18]. These structures were employed for further Patch Dock.

Target protein identification and preparation: The three dimensional (3D) structures of the Urocanase (PDB ID: 1UWL with resolution of $1.76 \mathrm{~A}$ ) and formiminoglutamase (FIGase) (PDB ID: 1XFK with resolution of $1.8 \mathrm{~A}$ ) were retrieved from the Research Collaborator for Structural Bioinformatics (RCSB) Protein Data Bank (www.rcsb.org) [19]. A chain of these proteins was processed individually by removing another chain (B, C and D), ligands in addition to the crystallographically experimental water particles (water without hydrogen bonds). The protein mentioned above was prepared using UCSF Chimera software (www.cgi.ucsf.edu/chimera).

ADME and toxicity prediction by Komputer-Assisted technology analysis: ADME (absorption, distribution, metabolism and excretion) analysis was performed by Swiss ADME $\&$ TOPKAT analysis were done using Discovery Studio (Pondicherry University) ADME analysis was performed using six descriptors such as human intestinal absorption, aqueous solubility, blood-brain barrier, cytochrome P450 2D6, Plasma protein binding and hepatotoxicity. As for the TOPKAT analysis, five descriptors were used which includes aerobic biodegradability (AB), Ames mutagenicity, ocular irritancy, skin irritancy and skin sensitization.

Docking studies: Docking studies were carried out by the PatchDock online server (http://bioinfo3d.cs.tau.ac.il/ PatchDock). PatchDock adopts geometry-based molecular docking algorithm method was used to recognize the binding scores, by binding residues atomic contact energy of the given ligands. The docking results were obtained through the email address. We also use to get uniform resource locator (URL), which provides the top 20 solutions in a table form via email. From these, the top one solution (the docked protein-ligand complex) was selected and downloaded in a database (pdb) file format. Further, the binding site analysis was carried out by PyMOL software (www.pymol.org).

\section{RESULTS AND DISCUSSION}

In general, biodegradation is a process in which environmental fate of a chemical can be assessed. In other words, it is the ability of any potent microorganisms to transform/use the harmful/hazards chemicals that enters the environment into non-hazardous/less hazards one. However, determining the biodegradation nature of compounds under in vitro condition is tedious and time consuming one [20]. To overcome these problem, molecular docking approaches has been explored in past years.

In earlier studies, we have prepared four different polybenzimidazole based polymers for metal extraction purpose, that resins are insoluble in organic solvents and nondegradable in nature, therefore need for the degradation pathways. In present study, four polybenzimidazole polymers with different units has selected, it could be beneficial to know the physico-chemical and drug-likeness properties of these polybenzimidazole polymers before carry out docking studies. Lipinski's rule of five was applied and additional helps to determine whether a principal composite having a certain pharmacological and biological actions might be done into an orally lively drug for human [21]. Violation of the Lipinski's rule of five is when $\log \mathrm{A}>5, \mathrm{MW}>500$, number of $\mathrm{N}, \mathrm{O}$ (hydrogen bond receptor) $>10$, number of $\mathrm{OH}$ and $\mathrm{NH}$ (hydrogen bond donor) $>5$ and number of the rotatable bond (rotb) $>15$. $m$-PBI, $p$-PBI single unit has shown 1 violations, $m$-PBI, $p$-PBI, py- $m$-PBI double unit and alkylated- $m$-PBI 
single and second unit has shown 2 violation. In addition, alkylated- $m$-PBI third unit showed 3 violation and rest of other PBIs third unit showed 4 violations and py- $m$-PBI single unit exhibited there is no violation. All the PBIs have above $500 \mathrm{MW}$ except $m$-PBI, $p$-PBI and py- $m$-PBI single unit, in addition, all the PBIs showed above $5 \log \mathrm{A}$ value (Table-1). These results shows that all PBIs does not obey the Lipinski's rule.

The drug-likeness score, if the score is $>0$ is active, -5.0 to -0.0 is moderate active and $<-5.0$ is inactive [22]. $m-P B I$,
$p$-PBI, py- $m$-PBI and alkylated- $m$-PBI single unit showed bioactive score in five descriptions. $m$-PBI, $p$-PBI, py- $m$-PBI and alkylated- $m$-PBI second and third units showed moderate bioactive score in all descriptions (Table-2). ADME prediction is also required before carrying out docking studies and which is commonly accepted in the primary step of medicine finding, drug screening, drug design, owing to its unique characteristic nature [23]. Table-3 showed the ADME profile of the PBI with different units. $m$-PBI, $p$-PBI, Py- $m$-PBI single unit have shown

\section{TABLE-1}

MOLECULAR PHYSICO-CHEMICAL DESCRIPTORS ANALYSIS OF FOUR PBIS WITH DIFFERENT UNITS USING MOLINSPIRATION ONLINE SOFTWARE TOOL

\begin{tabular}{|c|c|c|c|c|c|c|c|c|c|}
\hline Polymer resins* & $\log A^{a}$ & TPSA $^{\text {b }}$ & Natoms ${ }^{c}$ & $\mathrm{MW}^{\mathrm{d}}$ & $n o N^{e}$ & $\mathrm{nOH} \mathrm{NH}^{\mathrm{f}}$ & Nviolations $^{g}$ & Nrotb $^{h}$ & Volume ${ }^{\mathrm{i}}$ \\
\hline$m$-PBI, 1Unit & 5.87 & 57.37 & 27 & 352.44 & 4 & 2 & 1 & 3 & 326.43 \\
\hline$m$-PBI, 2 Unit & 9.34 & 114.73 & 51 & 660.78 & 8 & 4 & 2 & 6 & 590.29 \\
\hline$m$-PBI, 3 Unit & 10.17 & 172.10 & 75 & 969.13 & 12 & 6 & 4 & 9 & 854.16 \\
\hline$p$-PBI, 1 Unit & 5.89 & 57.37 & 27 & 352.44 & 4 & 2 & 1 & 3 & 326.43 \\
\hline$p$-PBI, 2 Unit & 9.19 & 114.73 & 50 & 646.76 & 8 & 4 & 2 & 5 & 573.49 \\
\hline$p$-PBI, 3 Unit & 10.11 & 172.10 & 74 & 955.10 & 12 & 6 & 4 & 8 & 837.36 \\
\hline Py-m-PBI, 1 Unit & 4.35 & 70.26 & 27 & 353.43 & 5 & 2 & 0 & 3 & 322.27 \\
\hline Py-m-PBI, 2 Unit & 8.23 & 140.52 & 51 & 662.76 & 10 & 4 & 2 & 6 & 581.98 \\
\hline Py- $m$-PBI, 3 Unit & 9.68 & 210.77 & 75 & 972.09 & 15 & 6 & 4 & 9 & 841.69 \\
\hline Alkyl- $m$-PBI, 1 Unit & 9.78 & 35.65 & 43 & 576.87 & 4 & 0 & 2 & 17 & 595.54 \\
\hline Alkyl- $m$-PBI, 2 Unit & 10.89 & 71.30 & 83 & 1109.65 & 8 & 0 & 2 & 34 & 1128.52 \\
\hline Alkyl-m-PBI, 3 Unit & 11.40 & 106.96 & 123 & 1642.42 & 12 & 0 & 3 & 51 & 1661.49 \\
\hline
\end{tabular}

${ }^{\mathrm{a}}$ Octanol-Water partition coefficient, ${ }^{\mathrm{b}}$ Polar surface area, ${ }^{\mathrm{c}}$ Number of non-hydrogen atoms, ${ }^{\mathrm{d}}$ Molecular weight, ${ }^{\mathrm{e}}$ Number of hydrogen bond acceptors [O and $\mathrm{N}$ atoms], ${ }^{\mathrm{f}}$ Number of hydrogen bond donors [OH and $\mathrm{NH}$ groups], ${ }^{\mathrm{g}}$ Number of Rule of 5 violations, ${ }^{\mathrm{h}}$ Number of rotatable bonds, ${ }^{\mathrm{i}}$ Molecular volume; *Unit 1, 2, 3 is n 1,2 and 3 .

TABLE-2

DRUG-LIKENESS PROPERTY ANALYSIS OF 4 PBIs WITH DIFFERENT UNITS USING MOLINSPIRATION ONLINE SOFTWARE TOOL

\begin{tabular}{|c|c|c|c|c|c|c|}
\hline Polymer resins & GPCR $^{*}$ ligand & $\begin{array}{c}\text { Ion channel } \\
\text { modulator }\end{array}$ & Kinase inhibitor & $\begin{array}{l}\text { Nuclear } \\
\text { receptor ligand }\end{array}$ & Protease inhibitor & Enzyme inhibitor \\
\hline$m$-PBI, 1Unit & 0.31 & 0.17 & 0.34 & -0.01 & 0.02 & 0.21 \\
\hline$m$-PBI, 2 Unit & -0.60 & -1.50 & -0.99 & -1.24 & -0.45 & -0.99 \\
\hline$m$-PBI, 3 Unit & -3.70 & -3.79 & -3.77 & -3.81 & -3.65 & -3.74 \\
\hline$p$-PBI, 1 Unit & 0.29 & 0.16 & 0.31 & -0.04 & -0.00 & 0.19 \\
\hline$p$-PBI, 2 Unit & -0.52 & -1.36 & -0.83 & -1.12 & -0.38 & -0.87 \\
\hline p-PBI, 3 Unit & -3.69 & -3.78 & -3.75 & -3.80 & -3.63 & -3.73 \\
\hline Py- $m$-PBI, 1 Unit & 0.48 & 0.34 & 0.54 & -0.04 & 0.18 & 0.36 \\
\hline Py- $m$-PBI, 2 Unit & -0.52 & -1.45 & -0.92 & -1.28 & -0.37 & -0.90 \\
\hline Py- $m$-PBI, 3 Unit & -3.68 & -3.78 & -3.75 & -3.81 & -3.64 & -3.73 \\
\hline Alkyl-m-PBI, 1 Unit & 0.10 & -0.45 & -0.15 & -0.30 & -0.05 & -0.13 \\
\hline Alkyl-m-PBI, 2 Unit & -3.82 & -3.88 & -3.88 & -3.90 & -3.80 & -3.85 \\
\hline Alkyl-m-PBI, 3 Unit & -4.05 & -4.07 & -4.07 & -4.08 & -4.04 & -4.05 \\
\hline
\end{tabular}

TABLE-3

ADME ANALYSIS OF TRIAZOLE DERIVATIVES USING SWISS ADME ONLINE TOOL

\begin{tabular}{lccccccccc}
\hline \multicolumn{1}{c}{ Polymer resin } & Gl $(\%)$ & BBB\# & $* *$ P-gp & $*$ CYP1A2 & ${ }^{*}$ CYP2C19 & *CYP2C9 & $*$ CYP2D6 & $*$ CYP3A4 & @log Kp \\
\hline$m$-PBI, 1Unit & High & No & Yes & Yes & Yes & No & Yes & Yes & -4.52 \\
$m$-PBI, 2 Unit & Low & No & No & No & No & No & No & No & -3.50 \\
$m$-PBI, 3 Unit & Low & No & Yes & No & No & No & No & No & -2.48 \\
$p$-PBI, 1 Unit & High & No & Yes & Yes & Yes & No & Yes & Yes & -4.52 \\
$p$-PBI, 2 Unit & Low & No & No & No & No & No & No & No & -3.72 \\
$p$-PBI, 3 Unit & Low & No & Yes & No & No & No & No & No & -2.70 \\
Py- $m$-PBI, 1 Unit & High & No & Yes & Yes & Yes & No & Yes & Yes & -5.23 \\
Py- $m$-PBI, 2 Unit & Low & No & No & No & No & No & No & No & -4.93 \\
Py- $m$-PBI, 3 Unit & Low & No & Yes & No & No & No & No & No & -4.63 \\
Alkyl- $m$-PBI, 1 Unit & Low & No & Yes & Yes & No & No & No & Yes & -1.20 \\
Alkyl- $m$-PBI, 2 Unit & Low & No & Yes & No & No & No & No & No & -3.14 \\
Alkyl- $m$-PBI, 3 Unit & Low & No & Yes & No & No & No & No & No & -7.48 \\
\hline
\end{tabular}

\%-Gastrointestinal, \#-Blood-brain barrier permeant, **-P-gp-P-glycoprotein substrate, CYP-Cytochrome P450, 8 Inhibitor, @-Skin Permeation $(\mathrm{cm} / \mathrm{s})$. 
TABLE-4

TOXICITY PREDICATION ANALYSIS OF PBI ANALOGUES USING DISCOVERY STUDIO SOFTWARE

\begin{tabular}{|c|c|c|c|c|c|c|c|}
\hline S. No. & Polymer resin & $\mathrm{AB}^{*}$ & $\mathrm{AM}^{* *}$ & $\mathrm{O}^{\mathrm{I \#}}$ & $\mathrm{SI}^{\# \#}$ & $\mathrm{SS}^{+}$ & $\mathrm{OT}^{++}$ \\
\hline 1 & $m$-PBI, 1Unit & Non-degradable & Non-mutagen & Irritant & Irritant & Sensitizer & 81.206 \\
\hline 2 & $m$-PBI, 2 Unit & Degradable & Non-mutagen & Irritant & Irritant & Sensitizer & 16.792 \\
\hline 3 & m-PBI, 3 Unit & Degradable & Non-mutagen & Irritant & Irritant & Sensitizer & 2.709 \\
\hline 4 & $p$-PBI, 1 Unit & Non-degradable & Non-mutagen & Irritant & Irritant & Non-Sensitizer & 35.606 \\
\hline 5 & $p$-PBI, 2 Unit & Degradable & Non-mutagen & Irritant & Irritant & Non-Sensitizer & 11.036 \\
\hline 6 & $p$-PBI, 3 Unit & Degradable & Non-mutagen & Irritant & Irritant & Sensitizer & 2.479 \\
\hline 7 & Py-m-PBI, 1 Unit & Non-degradable & Non-mutagen & Irritant & Irritant & Sensitizer & 30.815 \\
\hline 8 & Py-m-PBI, 2 Unit & Degradable & Non-mutagen & Irritant & Irritant & Sensitizer & 9.612 \\
\hline 9 & Py-m-PBI, 3 Unit & Degradable & Non-mutagen & Irritant & Irritant & Sensitizer & 24.589 \\
\hline 10 & Alkyl-m-PBI, 1 Unit & Degradable & Non-mutagen & Irritant & Irritant & Sensitizer & 7.103 \\
\hline 11 & Alkyl-m-PBI, 2 Unit & Degradable & Non-mutagen & Irritant & Irritant & Sensitizer & 1.578 \\
\hline 12 & Alkyl-m-PBI, 3 Unit & Degradable & Non-mutagen & Irritant & Irritant & Sensitizer & 2.340 \\
\hline
\end{tabular}

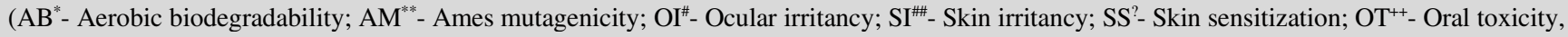
$\mathrm{g} / \mathrm{kg}$-body weight).

higher gastrointestinal (GI) absorption effect. On the other hand rest of the PBIs different unit has exhibited low gastrointestinal (GI) absorption effect. $m$-PBI, $p$-PBI, py- $m$-PBI single unit has predicted to CYP 1A2, CYP 2C19, CYP 2D6 and CYP 3A4 inhibition effect and $m$-PBI, $p$-PBI, py- $m$-PBI, alkylated- $m$ PBI third unit has predicted to have P-glycoprotein substrate inhibition effect.

The toxicity profile of polybenzimidazole analogous are listed in the Table- 4 , which shows $m$-PBI, $p$-PBI, py- $m$-PBI single unit non-degradable towards $\mathrm{AB}$ nature, on the other hand remaining PBIs units are degradable in nature. All the PBIs has shown ocular/eye irritancy and skin irritancy in humans.

Urocanate is first metabolic in the histidine degradation pathway, which is converted into 4-imidazolone-5-propionate by the enzymatic action of urocanase [24]. Urocanase has reported in bacteria, vegetables/mammals and plants. The pyridine based- $m$-PBI shown the highest atomic contact energy $(-368.86 \mathrm{kcal} / \mathrm{mol})$ and alkylated-m-PBI exhibited least ACE $(-123.83 \mathrm{kcal} / \mathrm{mol})$ with that of P. putida urocanase. The present finding is in good agreement with earlier report, where all PBIs single units are minimum degradable nature, but two or more units are degradable, while increasing the polymer chain length increasing the degradation ability. Alkylated- $m$-PBI third unit interacted with Asp 204 amino acid residue (Table-5) whereas Kessler et al. [24] reported that Asp 204 amino acid involves in acid-base catalytic reaction and Tyr 52 amino acid residue stabilize the positive charge of the substrate.

Similarly, the docking studies and binding site analysis in Table- 6 shows that pyridine based- $m$-PBI third unit have highest ACE $(-560.67 \mathrm{kcal} / \mathrm{mol})$, while $m$-PBI single unit have least ACE $(-120.86 \mathrm{kcal} / \mathrm{mol})$ values with that of $V$. cholera FIGase. The present finding was in good agreement with earlier report, where $m$-PBI single unit exhibited minimum degradation and pyridine based- $m$-PBI shown maximum degradation. These results might suggest that $m$-PBI single unit strongly exhibit FIGase activity and thus leads to minimum degradation. These studies Asp 89 \& 321 amino acid residue has been shown by three PBIs, namely, $m$-PBI single unit, $p$-PBI single unit and pyridine based- $m$-PBI.
TABLE-5

BINDING SITE ANALYSES OF POLYBENZIMIDAZOLE (PBI) ANALOGS WITH THAT OF UROCANASE USING PATCHDOCK

\begin{tabular}{|c|c|c|c|c|}
\hline $\begin{array}{l}\text { S. } \\
\text { No. }\end{array}$ & Polymer resin & $\begin{array}{c}-\mathrm{ACE} \\
(-\mathrm{kcal} / \mathrm{mol})\end{array}$ & $\begin{array}{l}\text { Interaction } \\
\text { of amino } \\
\text { acid residue }\end{array}$ & $\begin{array}{c}\text { Bond } \\
\text { distance } \\
(\AA)\end{array}$ \\
\hline 1 & $m$-PBI, 1Unit & 285.30 & Ser266 & 2.15 \\
\hline 2 & $m$-PBI, 2 Unit & 263.63 & $\begin{array}{l}\text { Tyr } \\
\text { Gln199 }\end{array}$ & $\begin{array}{l}2.10 \\
3.09\end{array}$ \\
\hline 3 & $m$-PBI, 3 Unit & 162.75 & $\begin{array}{l}\text { Gln41 } \\
\text { Ser402 } \\
\text { Ser402 }\end{array}$ & $\begin{array}{l}2.69 \\
2.96 \\
2.77\end{array}$ \\
\hline 4 & $p$-PBI, 1 Unit & 314.32 & $\begin{array}{l}\text { Gln264 } \\
\text { Ser266 }\end{array}$ & $\begin{array}{l}3.23 \\
3.04\end{array}$ \\
\hline 5 & p-PBI, 2 Unit & 242.96 & Gln199 & 1.84 \\
\hline 6 & $p$-PBI, 3 Unit & 183.49 & $\begin{array}{l}\text { Gln399 } \\
\text { Arg13 }\end{array}$ & $\begin{array}{l}2.13 \\
3.26\end{array}$ \\
\hline 7 & Py-m-PBI, 1 Unit & 334.40 & $\begin{array}{l}\text { Gln264 } \\
\text { Ser266 }\end{array}$ & $\begin{array}{l}2.94 \\
3.09\end{array}$ \\
\hline 8 & Py-m-PBI, 2 Unit & 142.46 & Gln208 & 3.36 \\
\hline 9 & Py-m-PBI, 3 Unit & 368.86 & $\begin{array}{l}\text { Ser402 } \\
\text { Gln41 } \\
\text { Ala14 }\end{array}$ & $\begin{array}{l}3.47 \\
3.23 \\
2.98\end{array}$ \\
\hline 10 & $\begin{array}{l}\text { Alkylated- } m \text {-PBI, } 1 \\
\text { Unit }\end{array}$ & 358.86 & $\begin{array}{l}\text { Ser266 } \\
\text { Asn45 }\end{array}$ & $\begin{array}{l}3.26 \\
3.36\end{array}$ \\
\hline 11 & $\begin{array}{l}\text { Alkylated- } m \text {-PBI, } 2 \\
\text { Unit }\end{array}$ & 123.83 & $\begin{array}{l}\text { No } \\
\text { interaction }\end{array}$ & Nil \\
\hline 12 & $\begin{array}{l}\text { Alkylated- } m \text {-PBI, } 3 \\
\text { Unit }\end{array}$ & 194.52 & $\begin{array}{l}\text { Asp204 } \\
\text { Gln480 }\end{array}$ & $\begin{array}{l}3.45 \\
2.33\end{array}$ \\
\hline
\end{tabular}

\section{Conclusion}

In the present study, all the tested PBI derivative different units have shown to dock with both targeted enzymes. However, $p$-PBI second unit and alkylated- $m$-PBI single unit does not interact with amino acid residues of FIGase also alkylated$m$-PBI second unit does not interact with amino acid residues of Urocanase. The toxicity profile of PBI derivatives shows $m$-PBI, $p$-PBI and pyridine- $m$-PBI single unit non-degradable towards $\mathrm{AB}$ nature. But others are degradable in nature. These observation suggested thta all the polybenzimidazole based polymer were degraded using these two degradation enzymes. 


\begin{tabular}{|c|c|c|c|c|}
\hline \multicolumn{5}{|c|}{$\begin{array}{c}\text { TABLE-6 } \\
\text { BINDING SITE ANALYSES OF POLYBENZIMIDAZOLE (PBI) } \\
\text { ANALOGS WITH THAT OF FORMIMINOGLUTAMASE (FIGase) } \\
\text { USING PATCHDOCK }\end{array}$} \\
\hline $\begin{array}{l}\text { S. } \\
\text { No. }\end{array}$ & Polymer resin & $\begin{array}{c}\text {-ACE } \\
(-\mathrm{kcal} / \mathrm{mol})\end{array}$ & $\begin{array}{l}\text { Interaction } \\
\text { of amino } \\
\text { acid residue }\end{array}$ & $\begin{array}{l}\text { Bond } \\
\text { distance } \\
(\AA)\end{array}$ \\
\hline \multirow[t]{3}{*}{1} & $m$-PBI, 1Unit & 120.86 & Asp284 & 2.72 \\
\hline & & & Asp321 & 2.43 \\
\hline & & & Glu328 & 2.80 \\
\hline 2 & $m$-PBI, 2 Unit & 305.73 & Gly12 & 3.20 \\
\hline \multirow[t]{3}{*}{3} & $m$-PBI, 3 Unit & 276.71 & Arg58 & 2.46 \\
\hline & & & $\operatorname{Arg} 173$ & 3.26 \\
\hline & & & Ser205 & 2.96 \\
\hline \multirow[t]{2}{*}{4} & $p$-PBI, 1 Unit & 179.20 & Asp89 & 3.12 \\
\hline & & & Leu90 & 3.22 \\
\hline 5 & $p$-PBI, 2 Unit & 520.11 & $\begin{array}{l}\text { No } \\
\text { interaction }\end{array}$ & Nil \\
\hline \multirow[t]{3}{*}{6} & $p$-PBI, 3 Unit & 416.73 & Thr10 & 1.92 \\
\hline & & & Leu90 & 3.19 \\
\hline & & & Asn92 & 3.16 \\
\hline 7 & Py-m-PBI, 1 Unit & 167.43 & Asp89 & 3.27 \\
\hline 8 & Py-m-PBI, 2 Unit & 560.67 & $\operatorname{Arg} 24$ & 3.06 \\
\hline \multirow[t]{4}{*}{9} & Py-m-PBI, 3 Unit & 229.82 & Glu57 & 2.57 \\
\hline & & & $\operatorname{Arg} 58$ & $2.11 \&$ \\
\hline & & & Thr164 & 3.31 \\
\hline & & & & 2.31 \\
\hline 10 & $\begin{array}{l}\text { Alkylated- } m \text {-PBI, } 1 \\
\text { Unit }\end{array}$ & 150.33 & $\begin{array}{l}\text { No } \\
\text { interaction }\end{array}$ & Nil \\
\hline \multirow[t]{2}{*}{11} & Alkylated- $m$-PBI, 2 & 342.63 & His159 & 2.91 \\
\hline & Unit & & Ser205 & 3.26 \\
\hline 12 & $\begin{array}{l}\text { Alkylated- } m \text {-PBI, } 3 \\
\text { Unit }\end{array}$ & 545.43 & $\operatorname{Arg} 317$ & 2.36 \\
\hline
\end{tabular}

\section{ACKNOWLEDGEMENTS}

The author thanks to Vel Tech Rangarajan Dr. Sagunthala R \& D Institute of Science and Technology (Deemed to be University), Chennai, India for their constant support. The authors also thanks Mr. Charles, Research Scholar, Department of Bioinformatics, Pondicherry University, Puducherry, India for helping to predict the toxicity effect of polybenzimidazole resins.

\section{CONFLICT OF INTEREST}

The authors declare that there is no conflict of interests regarding the publication of this article.

\section{REFERENCES}

1. M. Shimao, Curr. Opin. Biotechnol., 12, 242 (2001); https://doi.org/10.1016/S0958-1669(00)00206-8.
2. E.W. Choe and D.D. Choe, ed.: J.C. Salamone, Polymeric Materials Encyclopedia, CRC Press, New York, pp. 5619-5638 (1996).

3. H. Lee, D. Stoffey and K. Neville, New Linear Polymers, McGraw-Hill, New-York, Chap. 9 (1967).

4. A.H. Frazerr, High Temperature Resistant Polymers, Interscience, New York, vol. 138 (1968).

5. D.J. Jones and J. Roziere, J. Membr. Sci., 185, 41 (2001); https://doi.org/10.1016/S0376-7388(00)00633-5.

6. D. Mecerreyes, H. Grande, O. Miguel, E. Ochoteco, R. Marcilla and I. Cantero, Chem. Mater, 16, 604 (2004); https://doi.org/10.1021/cm034398k.

7. Q. Li, R. He, J.O. Jensen and N.J. Bjerrum, Fuel Cells, 4, 147 (2004); https://doi.org/10.1002/fuce.200400020.

8. K.Y. Wang, T.-S. Chung and R. Rajagopalan, Ind. Eng. Chem. Res., 46, 1572 (2007); https://doi.org/10.1021/ie061435j.

9. K.Y. Wang, T.-S. Chung and J.-J. Qin, J. Membr. Sci., 300, 6 (2007); https://doi.org/10.1016/j.memsci.2007.05.035.

10. Y. Wang, M. Gruender and T.-S. Chung, J. Membr. Sci., 363, 149 (2010); https://doi.org/10.1016/j.memsci.2010.07.024.

11. M. Chanda, K.F. O'Driscoll and G.L. Rempel, React. Polym. Ion Exchang. Sorb., 5, 157 (1987); https://doi.org/10.1016/0167-6989(87)90190-5.

12. M. Chanda, K.F. O'Driscoll and G.L. Rempel, React. Polym. Ion Exchang. Sorb., 7, 277 (1987);

https://doi.org/10.1016/0167-6989(88)90253-X.

13. M. Chanda and G.L. Rempel, React. Polym., 11, 165 (1989); https://doi.org/10.1016/0923-1137(89)90099-7.

14. D.-Y. Xing, S.-Y. Chan and T.-S. Chung, Green Chem., 14, 1405 (2012); https://doi.org/10.1039/c2gc35134j.

15. K.V. Peineman and S.P. Nunes, Membranes for Energy Conversion, Wiley-VCH (2008).

16. V. Vijayakumar, C.R. Kumar, A. Suresh, S. Jayalakshmi, U.K. Mudali, N. Sivaraman, Roy. Soc. Open Sci., 5, 171701 (2018); http://dx.doi.org/10.1098/rsos.171701.

17. R. Vijayakumar, S.S. Abd Gani and N.F. Mohd Mokhtar, Asian. J. Pharm. Clin. Res., 10, 251 (2017); https://doi.org/10.22159/ajpcr.2017.v10i8.19048

18. V. Vijayakumar, N. Radhakrishnan and C.R. Kumar, In Proceedings of IEEE International Conference on Smart Technologies and Management for Computing, Communication, Controls, Energy and Materials (ICSTM), pp. 513-516 (2017); https://doi.org/10.1109/ICSTM.2017.8089213.

19. R. Narayanaswamy, L. Kok Wai and I.S. Ismail, Int. J. Food Prop., 18, 2155 (2015);

https://doi.org/10.1080/10942912.2014.963870.

20. E. Rorije, F. Germa, B. Philipp, B. Schink and D.B. Beimborn, SAR QSAR Environ. Res., 13, 199 (2002); https://doi.org/10.1080/10629360290002271.

21. C.A. Lipinski, F. Lombardo, B.W. Dominy and P.J. Feeney, Adv. Drug Deliv. Rev., 46, 3 (2001); https://doi.org/10.1016/S0169-409X(00)00129-0.

22. S. Singh, A.K. Gupta and A. Verma, Res. J. Pharm. Biol. Chem. Sci., 4, 876 (2013).

23. J. Wang and L. Urban, Drug Discovery World, 5, 73 (2004).

24. D. Kessler, J. Retey and G.E. Schulz, J. Mol. Biol., 342, 183 (2004); https://doi.org/10.1016/j.jmb.2004.07.028. 